(d) At the Royal London Ophthalmic Hospital the almoner has a list of 249 societies which profess to give ophthalmic benefit, and members of these societies are not treated unless they are urgent cases. The surgeons decide as to whether cases are urgent or not.

(e) At the Royal Westminster and Central London Ophthalmic Hospitals insured patients are treated as ordinary cases except as under $(b)$.

$(f)$ Similarly diverse methods of procedure obtain in the Provincial Hospitals, some referring back members of approved societies, others treating them in the ordinary way.

\title{
Recommendations
}

(1) That every hospital keep a list as complete as possible of societies providing full ophthalmic benefit (vide first paragraph of this report) in order that the registration clerk or other officer may readily ascertain whether insured patients are entitled to such benefit.

(2) That patients entitled to full ophthalmic benefit be given a printed slip explaining how it may be obtained through their societies and be referred to their panel doctors.

(3) That notices be displayed in out-patient waiting halls calling attention to the provision of ophthalmic benefit by some societies, and advising insured patients to apply to the registration clerk or other officer of the hospital for information.

\section{THE ANNUAL CONGRESS OF THE OPHTHALMOLOGICAL SOCIETY OF THE UNITED KINGDOM, I927}

THE Ophthalmological Society of the United Kingdom held its Annual Congress this year, at Liverpool, on April 28, 29, and 30, under the presidency of Sir John H. Parsons. The proceedings were opened by the Lord Mayor of the city, Councillor F. C. Bowring, who also entertained the delegates to luncheon. In addition to a full scientific programme, and a well-organized clinical meeting, the social aspects of the Congress were well catered for, and an ophthalmological museum was provided by the good offices of Mr. Chavasse. The Edward Nettleship Medal for 1927 was presented to Mr. C. H. Usher of Aberdeen, the president-elect for the coming year, for his extensive investigations into the hereditary transmission of ocular diseases.

A full account of the papers and discussions will be published in the Transactions of the Society : merely an indication of the subjects of debate is given here. 
Mr. F. Treacher Collins read a paper on metaplasia of the tissues of the eyeball. He defined metaplasia as the production of specialized tissues from cells which normally produced tissue of other orders, owing to an alteration in environment, and not necessarily, or even primarily, in function; and he divided the metaplasias met with in the ocular tissues into embryological, pathological, neoplastic, and biological. Mr. R. A. Greeves described an operation for partial contraction of the socket, the essential feature of which consisted in the removal of fat and fibrous tissue. Dr. George Young discussed practical keratometry; and Dr. P. Stibbe demonstrated specimens illustrating the comparative anatomy of the nictitating membrane. Dr. Gordon Holmes dealt with tumours involving the chiasma, excluding those of the pituitary. Dr. A. W. M. Houwer presented a paper on keratitis filamentosa; Col. $\mathrm{H}$. Herbert one on glass membrane formation in irido-cyclitis; and Mr. G. F. Alexander discussed the causation of striate keratitis, and suggested a new method of controlling the eye in the operation for cataract. Mr. M. S. Mayou discussed the distension of the neural canal in the embryo in relation to microphthalmos. Mr. F. Juler described a case of sarcoma of the eyelid which was apparently cured by radium; and Mr. T. C. Summers dealt with a case of papilloedema occurring in a pedigree bull. Miss I. C. Mann communicated original embryological, histological, and clinical observations on the nature and boundaries of the vitreous. Embryologically it was shown to consist of three parts, a primary, derived from the optic vesicle and lens plate; a secondary, from the retina; and a tertiary, derived from the ciliary epithelium. She concluded that the vitreous is a gel enclosed within the meshes of a fibrous scaffold, and is not anywhere limited by a structureless membrane; that the fibrils are continuous with the Müllerian fibre system in the retina; that it is most strongly adherent at the ora serrata and along Egger's line on the capsule of the lens; and that the canal of Cloquet can under certain conditions be demonstrated by intra-vitam (slit-lamp) examination.

In addition to the papers there were two set debates, the first on nystagmus (other than miners'), the second, which produced many speakers, on the aetiology and treatment of hypopyon ulcer.

In opening the first, $\mathrm{Mr}$. Chavasse indicated the many points of view from which nystagmus could be regarded: as a simple movement, as a disease, as a symptom, as an adaptation to a habit, or as a problem in neurology. He insisted that the essential aspect of the problem was neurological, on which basis he discussed it at some length, dwelling especially on the differential diagnosis. If nystagmus in a case was jerking with a widespread field and it was uninfluenced by occlusion, it probably indicated a wide- 
spread affection. If the movements in the two eyes were dissociated, probably there was a comparatively peripheral lesion while an associated nystagmus would lead one to suspect a lesion in higher or more remote centres, influencing intact neuromuscular end-organs. Dr. Hugh Jones exhibited a model of the semicircular canals to show their relationship with other associated structures in various head postures, and followed this by demonstrating the absence of nystagmus after rapid rotation in a revolving chair in a patient who had lost the function of both labyrinths following acute influenza. Dr. Gordon Holmes pointed out that there must be taken into account vestibular components which compensated movements of the head and body, visual components which compensated movements of the eyes, and voluntary components which adjusted the eyes, as well as the stimuli of sight in the field of vision. Of these the vestibular components were the most important. Nystagmus depended essentially on lesions of those paths and centres which were limited to the hind-brain and intimately connected with the vestibular apparatus, and, in his opinion, never arose from a lesion of the fore-brain. It might occur in asthenic states and intoxications, and might also be the result of a defective fixation reflex; but in all cases it was a definite co-ordinated act, which could occur even when the muscles were partially paralyzed, and it should never be regarded merely as a "tremor of the eyes." Mr. Sidney Scott discussed the subject from the point of view of the otologist, dealing with nystagmus as a manifestation of labyrinthine disease occurring in persons with normal vision. Several others joined in the discussion.

The debate on the aetiology and treatment of hypopyon ulcer was opened by Mr. Grey Clegg with an exhaustive statistical account of the factors concerned in its incidence, and a résumé of the therapeutic measures which have been advocated from time to time : local medicaments, heat, caustics, radiation, and operative interference. The bacteriological side of the question was dealt with by Dr. S. H. Browning, who insisted on the frequency of the pneumococcus in association with the condition, although the most virulent organism was the $B$. pyocyaneus. Oral infection also was an important factor. Treatment by purely bacteriological methods was on the whole unsatisfactory. Mr. M. S. Mayou also discussed the bacteriology involved, paying particular attention to the activities of the gonococcus. Mr. McMullen emphasized the importance of oral sepsis. Mr. Hudson discussed the operative treatment and advised the early resort to a Saemisch section when the tension rose, and suggested a method of dealing with complicating iris-inclusions. New methods of techniaue in this operation were described by Col. H. Herbert and Mr. C. Reid, 
both of whom advocated a T-shaped incision, the former through the ulcer, the latter peripherally and extending up to the ulcer. Many other speakers entered into the discussion, prominent among whom was Dr. Freeland Fergus, who insisted on the importance of prophylactic measures, and gave a refreshing account of the treatment which he had relied upon with success for many years, which consisted in essence of the absence of bandaging and ointments, and the employment of continuous bathings and miotics. On the whole with its multitude of remedies and many conflicting opinions, the debate made clear the unsatisfactory state of our present means of dealing with this common and mutilating condition.

W. S. DUKE-ELDER.

\section{ABSTRACTS}

\section{I.-DISEASE OF UVEA}

(1) de Schweinitz, G. E. (Philadelphia).-The clinical features and aetiologic factors of progressive atrophy of the iris and the formation of holes in its tissue. Trans. Amer. Ophthal. Soc., Vol. XXIV, 1926.

(1) de Schweinitz gives in this paper the subsequent history of a case of this rare affection, a case which was first recorded by him in 1915, and discusses the various theories that may be held to account for it. The patient was a woman, aged 23 years, with no noteworthy points in her family history. In addition to measles, scarlet fever, whooping cough, pneumonia and pleurisy she had suffered from adenitis of the neck and suppuration of the axillary glands. Her eyes were examined during her school life and found to be normal. The first alteration, in the shape of an egg-shaped pupil with evidence of thinning and degeneration of the iris of the left eye, was noticed in 1912. The condition rapidly progressed, and the first rise of intraocular pressure was noted in 1914. Operation was refused and by the end of 1920 the glaucoma was absolute. In 1921 the patient had a severe attack of retrobulbar neuritis in the right eye which had previously been normal. Although this cleared up completely with normal vision, symptoms pointing to disseminated sclerosis made their appearance. The changes in the iris are illustrated by a black and white plate showing three different stages, and an excellent coloured plate 